\title{
Production of Biodiesel from Cottonseed Oil over Aminated Flax Fibres Catalyst: Kinetic and Thermodynamic Behaviour and Biodiesel Properties
}

\author{
Rihab Musaad Moawia ${ }^{1}$, Mohamed Mahmoud Nasef ${ }^{2,3}{ }^{*}$, Nor Hasimah Mohamed ${ }^{4}$, \\ Adnan Ripin1, Hamdy Farag5,6 \\ ${ }^{1}$ School of Chemical and Energy Engineering, Universiti Teknologi Malaysia, Skudai, Malaysia \\ ${ }^{2}$ Chemical Engineering Department, Universiti Teknologi PETRONAS, Seri Iskandar, Malaysia \\ ${ }^{3}$ Malaysia Japan International Institute of Technology, Universiti Teknologi Malaysia Kuala Lumpur, Kuala Lumpur, Malaysia \\ ${ }^{4}$ Radiation Processing Technology Division, Malaysian Nuclear Agency, Kajang, Malaysia \\ ${ }^{5}$ Chemistry Department, Faculty of Science, Mansoura University, Mansoura, Egypt \\ ${ }^{6}$ Department of Material Process Engineering, Graduate School of Engineering, Kyushu University, Fukuoka, Japan \\ Email: *mahmoudeithar@cheme.utm.my
}

How to cite this paper: Moawia, R.M., Nasef, M.M., Mohamed, N.H., Ripin, A. and Farag, H. (2019) Production of Biodiesel from Cottonseed Oil over Aminated Flax Fibres Catalyst: Kinetic and Thermodynamic Behaviour and Biodiesel Properties. Advances in Chemical Engineering and Science, 9, 281-298.

https://doi.org/10.4236/aces.2019.94021

Received: July 13, 2019

Accepted: September 9, 2019

Published: September 12, 2019

Copyright $\odot 2019$ by author(s) and Scientific Research Publishing Inc. This work is licensed under the Creative Commons Attribution International License (CC BY 4.0).

http://creativecommons.org/licenses/by/4.0/

c) (†) Open Access

\begin{abstract}
The transesterification of cottonseed oil in the presence of methanol to fatty acid methyl ester (FAME) using flax-based fibres catalyst modified with an alkaline moiety was studied. The catalyst was prepared by radiation induced grafting (RIG) of glycidyl methacrylate (GMA) onto dignified flax fibres followed by amination with diethylamine (DEA) and treatment with $\mathrm{NaOH}$ solution. A maximum FAME conversion of $88.6 \%$ was obtained at $60^{\circ} \mathrm{C}$ with a catalyst dosage of $2.5 \mathrm{wt} \%$, an oil/methanol ratio of $1: 33$ and a time of $2 \mathrm{~h}$. The biodiesel quality was verified by nuclear magnetic resonance ( ${ }^{1} \mathrm{H}$ NMR). Kinetic analysis showed a reaction activation energy of $69.33 \mathrm{~kJ} \cdot \mathrm{mol}^{-1}$ and a rate constant of $0.00349 \mathrm{~min}^{-1}$ indicating that the catalytic reaction was kinetically controlled. Thermodynamic analyses revealed that the reaction was reversible, non-spontaneous and endothermic with an enthalpy of 66.62 $\mathrm{kJ} \cdot \mathrm{mol}^{-1}$. The obtained biodiesel showed physical and chemical characteristics complying with ASTM D6751. It can be concluded that the alkaline biopolymer catalyst prepared in the present study is a promising green candidate for biodiesel production.
\end{abstract}

\section{Keywords}

Biodiesel Production, Radiation Grafted Basic Flax Fibres Catalyst, 
Cottonseed Oil, Transesterification Kinetics and Thermodynamics, Radiation Induced Grafting

\section{Introduction}

Biodiesel is an alternative fuel to petro-diesel derived from renewable resources including vegetable oils. The advantages of biodiesel such as biodegradability, sustainability, non-toxicity and low gas emissions (e.g. $\mathrm{SO}_{\mathrm{x}}$ and $\mathrm{NO}_{\mathrm{x}}$ emission) made it promising fuel for reduction of greenhouse gas emission and mitigation of climate change. This has led to a major surge in the biodiesel production in the past few decades [1].

Biodiesel is fatty alkyl esters that are commonly obtained by transesterification of triglycerides in vegetable oils with methanol yielding mixtures of fatty acid methyl esters (FAME). Transesterification is widely carried out using homogenous basic catalysts like alkaline metal alkoxides or hydroxides. However, this process has low production efficiency caused by complicated downstream processing involving high cost and energy consumption for the recovery of excess methanol and catalyst in addition to massive water discharge despite FAME high yield. Thus, the interest in the development of heterogeneous catalysts for improving biodiesel production gained an increasing interest because of their advantages pertaining to cost reduction and environmental protection compared to homogeneous catalysts [2] [3].

Various types of heterogeneous catalysts with established kinetics have been used for production of biodiesel through transesterification and esterification reactions. Majority of tested heterogeneous catalysts for biodiesel production are inorganic materials [3]. Many solid acidic and basic inorganic catalysts have been studied for the transesterification of various vegetables oils. Solid base catalysts (e.g. cheap alkaline earth metal oxides) have been found to be effective in transesterification of vegetable oils with low free fatty acids (FFA) content compared to most of the solid acid catalysts. However, these catalysts are very sensitive to water, $\mathrm{CO}_{2}$ and FFA content, which eventually deactivates the catalyst by saponification [4].

Polymer catalysts with ionic groups have been proposed as alternatives to inorganic catalysts. Particularly, ionic materials such as ion exchange resins and their corresponding functionalized polymeric materials have been considered for replacing heterogeneous catalysts for transesterification and esterification reactions for biodiesel production [2]. The catalytic activity of such materials depends heavily on the number of functional groups (active sites) and their accessibility by the reaction mixtures [5]. Thus, the application of ion exchange resins for catalysis depends heavily on the resin morphology [6] [7] [8]. However, resins with their porous structures have slow kinetics and mass transfer limitations and thus, catalysts with fibrous substrates have potential to overcome such limi- 
tations by providing better access to active sites.

The potential of application of fibrous basic catalyst prepared by radiation induced grafting (RIG) of vinylbenzyl chloride onto polyethylene (PE) nonwoven sheet followed by amination for transesterification of triolein with various types of alcohols was investigated [9] [10]. Similar radiation grafted and aminated catalyst based on $\mathrm{PE} /$ polypropylene (PE/PP) nonwoven sheet was evaluated for transesterification of triacetine [11]. The potential of replacing synthetic PE and PE/PP substrates with flax (Linum usitatissimum) [12] and kenaf [13] fibres for preparation of aminated radiation grafted polymer catalyst based on natural fibres was recently explored. The preparation process involved RIG of glycidyl methacrylate (GMA) and subsequent amination with diethylamine and the obtained catalyst was preliminarily tested for transesterification of cottonseed oil/methanol [14]. The use of such natural fibres having low cost and good tensile strength [15] is motivated by the environmental friendless of lignocellulosic biomass and the ability to functionalise natural fibres, ease of handling, recoverability and higher supporting capacities than of synthetic resins counterparts [16]. Despite the green preparation route, value added to flax fibres and promising performance of radiation grafted catalyst based on aminated flax fibres in biodiesel production, no kinetic and thermodynamic investigations were conducted to assist further development and scaling up of transesterification reaction in addition to absence of any investigation on the quality of biodiesel obtained with this type of catalysts.

The objective of this study is to investigate kinetics and thermodynamics of transesterification of cottonseed oil in presence of methanol over the new basic biopolymer catalyst containing diethylamine (DEA)/poly(GMA) grafted on flax fibres. Such kinetic investigations is highly important for designing a scaled production process and it involves determination of reaction rates, rate constants and activation energy. The enthalpy, entropy and Gibbs free energy were also calculated. The physico-chemical characteristics of the obtained biodiesel were evaluated. The selection of cottonseed oil as a source of triglyceride together and flax fibres as substrate for catalyst making was motived by their low cost and abundance in countries like Sudan and Egypt.

\section{Experimental}

\subsection{Materials}

Flax fibres were obtained from Tanta Flax Ltd. Co. (Egypt). GMA monomer with 97\% purity, polyoxyethylene sorbitan monolaurate (Tween-20) and isopropanol were purchased from Sigma Aldrich. Sodium hydroxide (97\%), sodium chlorite $(80 \%)$ and nitric acid $(\geq 65 \%)$ were obtained from Sigma Aldrich and used to prepare the needed solutions in deionized water (DI). DEA (99.5\%), methanol (99.8\%) were purchased from Sigma Aldrich. All chemicals were used without further purification. Cottonseed oil (low grade) was obtained from a commercial supplier in Sudan and used as a source of triglycerides for biodiesel production. 


\subsection{Characterizations of Cottonseed Oil}

The cotton seed oil properties such as saponification value, acid number and FFA contents were determined according to the Standard Methods of the American Oil Chemists' Society, AOCS.

\subsection{Preparation of Aminated Poly(GMA) Grafted Flax Fibres Catalyst}

The catalyst obtained in this study was prepared in 3 steps involving: 1) irradiation of delignified flax fibres, 2) RIG of grafting of GMA onto irradiated flax fibres and 3) treatment of grafted fibres with DEA and $\mathrm{NaOH}$. The flax fibres were placed in a PE bag, which was sealed after blowing with purified $\mathrm{N}_{2}$ and irradiated with an electron beam accelerator (Nissin High Voltage, Model: EPS 3000 , Japan) over dry ice to a dose of $20 \mathrm{kGy}$ at $5 \mathrm{kGy} /$ pass. The irradiated flax fibres were removed and stored under freezing conditions of $-40^{\circ} \mathrm{C}$ overnight before it was reacted with deoxygenated emulsion solution comprising of $5 \%$ GMA containing $0.5 \%$ Tween 20 surfactant at $40^{\circ} \mathrm{C}$ for $1 \mathrm{~h}$. The grafted fibres were removed, rinsed and washed few times with methanol to completely remove any homopolymer. The degree of grafting (DG) was determined from the weight increase after grafting and was found to be $148 \%$ under the present conditions. More details on the preparation procedure can be found elsewhere [12]. The poly(GMA) grafted flax fibres [Flax- $g$-poly(GMA)] were aminated to a maximum amine density of $3.66 \mathrm{mmol} / \mathrm{g}$, which was achieved at $80 \% \mathrm{EDA}$ concentration, $80^{\circ} \mathrm{C}$ reaction temperature and $3 \mathrm{~h}$ reaction time [14]. The obtained functionalised fibres denoted as Flax- $g$-poly(GMA)/DEA was rinsed in $1 \mathrm{M}$ $\mathrm{NaOH}$ solution for $16 \mathrm{~h}$ to introduce $\mathrm{OH}^{-}$as a counter ion [11].

The total specific surface areas of the aminated catalyst and its corresponding grafted and delignified flax fibres were determined with $\mathrm{N}_{2}$ as an adsorbate using $1 \mathrm{~g}$ of the sample using the Brunauer-Emmett-Teller (BET) technique by a Micromeritics' Gemini VII 2390 surface area analyser.

\subsection{Transesterification of Cottonseed Oil with Methanol}

The performance of the new catalyst [Flax- $g$-poly(GMA)/DEA] was evaluated for transesterification of cottonseed oil and methanol in a batch mode according to the procedure described in the literature and the conversion of fatty acid methyl ester (FAME) was mentioned using ${ }^{1} \mathrm{H}$ NMR. The Flax- $g$-poly(GMA)/DEA was treated with $1 \mathrm{M} \mathrm{NaOH}$ aqueous solution followed by washing with DI water and drying prior to use [17]. The catalyst and methanol were placed in 3-neck-round flask and the mixture was shacked for $10 \mathrm{~min}$ to swell the catalyst. The cottonseed oil was then introduced and the mixture was vigorously stirred using a magnetic stirrer at $300 \mathrm{rpm}$. The mixture was heated to different temperatures in an oil bath for various periods of time. The kinetics and thermodynamic investigations were evaluated for transesterification of cottonseed oil/methanol mixture at an optimum catalyst loading of $2.5 \mathrm{wt} \%$ and oil/methanol ratio of 1:33. The reaction time and temperature were varied in the ranges of $30-120$ 
mins and $45^{\circ} \mathrm{C}-65^{\circ} \mathrm{C}$, respectively. The sampling process involved taking $5 \mathrm{ml}$ of FAME samples at the desired temperature and time before transferring to ice bath to stop the reaction. After cooling, the samples were centrifuged to obtain the biodiesel samples required for the kinetic and thermodynamic investigations.

\subsection{Evidence of FAME Conversion}

The obtained products of the transesterification reaction were analysed using the Bruker Advance II $400 \mathrm{MHz}$ model, ${ }^{1} \mathrm{H}$ NMR. The analysis was carried out by dissolving $0.050 \mathrm{~mL}$ of FAME sample in $0.5 \mathrm{~mL}$ of $99 \%$ deuterated chloroform $\left(\mathrm{CDCl}_{3}\right)$ and placed in the sample tubes. The sample was shaken carefully and transferred to the NMR probe (with $5 \mathrm{~mm}$ internal diameter) before analysis. The resulting spectra were recorded at room temperature and the obtained data was processed using Topsin software (version 3.1). Subsequently, the ${ }^{1} \mathrm{H}$ NMR spectra were used to identify the biodiesel products. The percentage of conversion to FAME was calculated according to the following equation [18].

$$
\% \text { Conversion to FAME }=\left[\left(A_{1} / 3\right) /\left(A_{2} / 2\right) \times 100\right]
$$

where, the terms $A_{1}$ represents the area of methoxy protons from methyl esters at chemical shift of 3.68 (singlet peak) and $A_{2}$ is the area of methylene protons from the triglycerides at chemical shifts of $2.30 \mathrm{ppm}$ (triplet peak). The factors 3 and 2 are derived from the number of attached protons at the methoxy and methylene carbons.

\subsection{Characterisation of Biodiesel}

The physico-chemical characteristics of FAME obtained from transesterification of cottonseed oil with methanol were evaluated according to ASTM standard tests presented in Table 1.

\subsection{Reaction Kinetics}

The pseudo-first order model was adopted for the transesterification reaction in this study because an excess methanol to oil ratio (33:1) was used compared to the stoichiometric molar ratio of 3:1 required for this reaction. Considering such methanol excess, the rate law equation used to express the reaction in this study is as follows:

Table 1. Lists of the specifications ASTM biodiesel standard test.

\begin{tabular}{cc}
\hline Quality test & Standard methods \\
\hline Pour point $(\mathrm{min})$ & D 97 \\
Kinematic viscosity at $40^{\circ} \mathrm{C}\left(\mathrm{mm}^{2} / \mathrm{s}\right)$ & D 445 \\
Flash point $\left({ }^{\circ} \mathrm{C}\right)$ & D 93 \\
Density at $30^{\circ} \mathrm{C}\left(\mathrm{mg} / \mathrm{cm}^{3}\right)$ & D 6751 \\
Cloud point $\left({ }^{\circ} \mathrm{C}\right)$ & D 2500 \\
Cetane number & D 613
\end{tabular}




$$
-\ln (1-x)=k t
$$

where, $k$ is the apparent rate constant, $t$ is reaction time and $x$ is cottonseed oil concentration converted to FAME [19] [20]. Consequently, the temperature dependent rate constant, $k$ was deduced from the slope of the line obtained by plotting $-\ln (1-x)$ against time $(t)$ [21]. Moreover, the activation energy was determined in the temperature range of $45^{\circ} \mathrm{C}-65^{\circ} \mathrm{C}$ using the Arrhenius equation [22]:

$$
\ln k=\ln A-\frac{E_{a}}{R T}
$$

where, $k$ represents the apparent reaction rate constant, $A$ is pre-exponential factor, $E_{a}$ is the activation energy $(\mathrm{kJ} / \mathrm{mol}), R$ is the universal gas constant and $T$ is the reaction temperature $(K)$.

\subsection{Thermodynamics of the Reaction}

The thermodynamic parameters such as enthalpy $\left(\Delta \mathrm{H}^{*}\right)$ of transesterification was obtained using Eyring equation [20]:

$$
\ln \left(\frac{k}{T}\right)=-\frac{\Delta H^{*}}{R}\left(\frac{1}{T}\right)+\left[\left(\ln \frac{k_{B}}{h}\right)+\frac{\Delta S^{*}}{R}\right]
$$

where, $k$ is the apparent rate constant, $T$ is the temperature, $R$ is universal gas constant $\left(8.314 \mathrm{~J} \cdot \mathrm{mol}^{-1} \cdot \mathrm{K}^{-1}\right), k_{B}$ is Boltzman's constant $\left(1.38 \times 10^{-23}\right), h$ is Plank's constant $\left(6.63 \times 10^{-34}\right)$ and $\Delta S^{*}$ is the entropy of transesterification. The entropy $\left(\Delta S^{*}\right)$ was determined from the intercept of the Eyring equation plot as expressed in Equation (5):

$$
\text { Intercept }=\left[\left(\ln \frac{k_{B}}{h}\right)+\frac{\Delta S^{*}}{R}\right]
$$

The Gibbs' free energy $\left(\Delta G^{*}\right)$ was calculated using Equation (6):

$$
\Delta G^{*}=\Delta H^{*}-T \Delta S^{*}
$$

\subsection{Catalyst Deactivation Studies}

The deactivation of prepared alkaline catalyst was observed for 4 cycles using a mixture of cottonseed oil/methanol solution at optimum conditions of oil-methanol molar ratio of $1: 33$, catalyst concentration of $2.5 \mathrm{wt} \%$ (catalyst/oil), reaction temperature of $60^{\circ} \mathrm{C}$ and time of $2 \mathrm{~h}$. After each reaction, the catalyst was recovered by filtration followed by washing with methanol and 5\% (v/v) citric acid and thereafter by treatment with $1 \mathrm{M} \mathrm{NaOH}$ according to the procedure reported by elsewhere [9].

\section{Results and Discussion}

\subsection{Properties of Cottonseed Oil}

The content of FFA and water are well known to affect the selection of the catalyst of biodiesel production [2]. Particularly, it is well established that the high 
FFA and water contents lead to the production of large amounts of soap, which in turn lower the yield of FAME and makes its separation from glycerol difficult. The results of the analysis of cottonseed oil presented in Table 2 shows a negligible moister content $(0.05 \%)$, a low FFA value $(0.35 \%)$ and a low acid value $(0.36$ $\mathrm{mg} \mathrm{KOH} / \mathrm{g}$ ). Such low FFA content confirms that transesterification with alkaline polymer catalyst is suitable for producing biodiesel from cottonseed oil in this study. Similar low FFA values were reported in literature for refined cottonseed oil [23] and its raw counterparts [24] [25].

The ${ }^{1} \mathrm{H}$ NMR spectrum for cottonseed oil is presented in Figure 1. A number of characteristic peaks resembling the triglycerides in cottonseed oil can be observed. Particularly, the peaks at $\delta 0.80-1.01 \mathrm{ppm}$ correspond to the protons of the terminal methyl group whereas, the peaks in the range of $\delta 1.20-1.41 \mathrm{ppm}$ represent the protons of all the internal $\mathrm{CH}_{2}$ groups available in the fatty acid backbone [26]. The peaks shown at $\delta 1.53-1.70 \mathrm{ppm}$ stand for the protons of $\mathrm{CH}_{2}$ group neighbouring the terminal methyl group. The peaks at $\delta 1.94-2.11$ ppm are assigned for allylic protons of $-\mathrm{CH}_{2}$, whereas the peaks at $\delta 2.28-2.35$ and $2.74-2.78 \mathrm{ppm}$ represent the $\alpha$-protons of the ester groups and $\mathrm{CH}_{2}$ of double allylic protons, respectively. The doublet peaks at $\delta 4.09-4.34 \mathrm{ppm}$ are assigned for protons in $-\mathrm{CH}_{2}\left(\mathrm{C}_{1}\right.$ and $\left.\mathrm{C}_{3}\right)$ of glyceride moiety [27]. The peak at 5.25 is assigned for methinine protons present at $\mathrm{C}_{2}$ of glyceride. The peaks appears at $\delta 5.28-5.43 \mathrm{ppm}$ for protons of the olefinic $(-\mathrm{CH}=\mathrm{CH})$ moiety. It can be concluded that the characteristic peaks of the triacylglycerol chains in cottonseed oil are in a complete agreement with the literature [28].

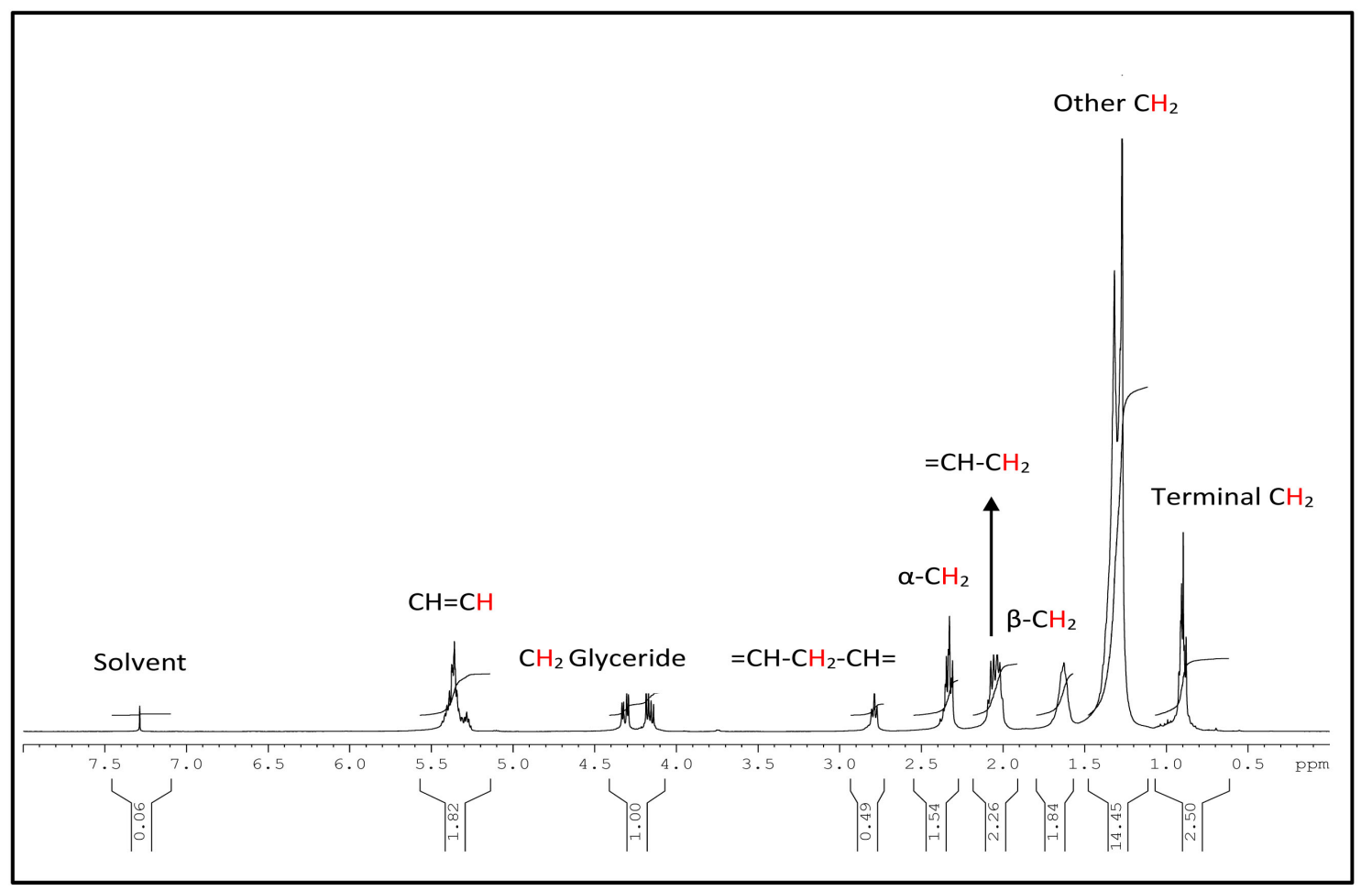

Figure 1. ${ }^{1} \mathrm{H}$ NMR Spectra of cottonseed oil. 
Table 2. Physico-chemical properties of cottonseed oil.

\begin{tabular}{ccc}
\hline Quantity & Units & Feedstock \\
\hline Moisture (hot plate) & $\%$ & 0.05 \\
Saponification value & $\mathrm{mg} \mathrm{KOH} / \mathrm{g}$ & 199.7 \\
Free fatty acid & $\%$ & 0.35 \\
Iodine value & - & 98.4 \\
Acid value & $\mathrm{mg} \mathrm{KOH} / \mathrm{g}$ & 0.36 \\
Density $\left(30^{\circ} \mathrm{C}\right)$ & $\left(\mathrm{mg} / \mathrm{cm}^{3}\right)$ & 0.8752 \\
Kinematic viscosity $\left(40^{\circ} \mathrm{C}\right)$ & $\mathrm{mm} / \mathrm{s}$ & 33.1 \\
\hline
\end{tabular}

\subsection{Properties of the Alkaline Biopolymer Catalyst}

A new alkaline catalyst containing aminated poly(GMA) grafts covalently bonded to flax fibres and complexed with $\mathrm{OH}^{-}$counter ion was prepared by RIG of GMA onto delignified flax fibres followed by functionalisation with EDA and treatment with $\mathrm{NaOH}$ solution. The evidence of chemical changes accompanied incorporation of poly(GMA) and subsequent immobilization of EDA was in forms of two levels of feature changes as reported in our latest study [29]. Grafting was reported to impart chemical changes represented by the appearance of acrylate and epoxy related peaks in the grafted fibres. The introduction of DEA imparted amine $\left(-\mathrm{NH}_{2}\right)$ peaks overlapping with hydroxide $(-\mathrm{OH})$ that was coupled with a substantial reduction in the epoxy rings peaks. The amine density in the obtained catalyst was found to be $3.65 \mathrm{mmol} \cdot \mathrm{g}^{-1}$ and a degree of amination close to $100 \%$ was achieved using the adopted procedure [29].

The SEM images of raw, bleached, poly(GMA) grafted and aminated flaxfibres imported morphological changes in the flax fibres as reported elsewhere [12]. The raw flax fibre displayed a rough surface with a network structure comprising tight bundles of microfibrils bound together by hemicellulose. This was changed to cleaner and smooth surface in bundles of continuous cellulose microfibrils aligned along the fibres' direction. The introduction of poly(GMA) grafts imparted thick layers to the delignified flax microfibrils causing an increase in fibre diameters compared to the raw and bleached fibres. Additional increase in the diameter after amination of the grafted fibres with swelling causing some microfibrils structure to purse [29]. The published FTIR and SEM results provided strong evidence for grafting and amination of the fibres investigated.

A summary of the BET-adsorption properties of Flax- $g$-poly(GMA)/DEA catalyst together with the corresponding grafted and original flax fibres is presented in Table 3. The total specific surface area was $5.9 \mathrm{~cm}^{3} \cdot \mathrm{g}^{-1}$ with pore volume of 55 $\left(\mathrm{mm}^{3} \cdot \mathrm{g}^{-1}\right)$. Apparently, such values were increased starting from the untreated flax, delignified flax and grafted flax fibres and this trend is caused by incorporation of poly(GMA) and DEA in the flax fibres after each treatment. 
Table 3. BET data for flax- $g$-poly(GMA)/DEA catalyst.

\begin{tabular}{ccc}
\hline Samples & Specific surface area $\left(\mathrm{cm}^{3} \cdot \mathrm{g}^{-1}\right)$ & Pore volume $\left(\mathrm{mm}^{3} \cdot \mathrm{g}^{-1}\right)$ \\
\hline Untreated flax & 0.33 & 32 \\
Delginfied flax & 0.63 & 40 \\
Flax- $g$-poly(GMA) & 1.3 & 35 \\
Flax- $g$-poly(GMA)/DEA & 5.9 & 55 \\
\hline
\end{tabular}

\subsection{Effect of Temperature on Conversion to FAME}

The variation of conversion to FAME with the reaction time at different temperatures is shown in Figure 2. As can be observed, from one hand, there is a gradual increase in the conversion as the time prolonged at all temperatures. On the other hand the rise in the temperature from $45^{\circ} \mathrm{C}$ to $60^{\circ} \mathrm{C}$ led to an increase in the FAME conversion beyond which it started to decline. The former trend was due to the increase in the access of the reactants to the active groups available on catalyst with longer reaction times whereas the conversion-temperature dependence is most likely caused by the higher energy state of the molecules resulting in a reduction in the viscosity of reaction mixture that prompted more effective interactions accelerating conversion to FAME. When the temperature increased to $65^{\circ} \mathrm{C}$, methanol started to evaporate and thus the reaction rate started to decline [30] [31]. The results of this study is at par with the transesterification of cottonseed oil using a liquid alkaline catalyst $(\mathrm{NaOH})$ of $1 \mathrm{wt} \%$ concentration at 1:6 oil/methanol molar ratio, $60^{\circ} \mathrm{C}$ temperature and 90 min reaction time that yielded $93 \%$ maximum FAME conversion [24]. A close yield of $92 \%$ biodiesel was also reported when cottonseed oil was transesterified with methanol using $\mathrm{CaO}$ catalyst at reaction temperature, time, methanol/oil ratio and catalyst loading rate of $60^{\circ} \mathrm{C}, 50 \mathrm{~min}, 12: 1$ and $3 \%(\mathrm{wt} \%$ ), respectively [32].

\subsection{Evidence of Biodiesel Formation}

The analysis of biodiesel considered in this study is based on the fact that the amplitude of a proton nuclear magnetic resonance ( $\left.{ }^{1} \mathrm{H} N \mathrm{NR}\right)$ signal is proportional to the number of hydrogen nuclei contained in the molecule. The presence of FAME i.e., biodiesel could be observed when standard biodiesel spectrum depicted in Figure 3 is compared with that of cottonseed oil shown in Figure 1. A summary of the assignments of the peaks of 1 NMR spectrum of FAME and that of cottonseed oil is presented in Table 4 . The $-\mathrm{CH}_{2}$ protons related to the glyceride of cottonseed oil, which appeared at the range of $\delta 4.09$ $4.34 \mathrm{ppm}$ in Figure 1 is completely disappeared. This was accompanied by the appearance of a strong peak at $\delta=3.68 \mathrm{ppm}$ representing $-\mathrm{OCH}_{3}$ related to FAME [33]. The conversion (\%) of triglyceride to FAME was calculated by taking the ratio of peak area of methoxy protons from methyl esters which appears at $\delta=$ $3.68 \mathrm{ppm}$ whereas the methylene proton was at $\delta=2.3 \mathrm{ppm}$ as given in Equation (1) [18]. These results confirm the formation of FAME as a result of transesterification of cottonseed oil and methanol under the investigated conditions. 


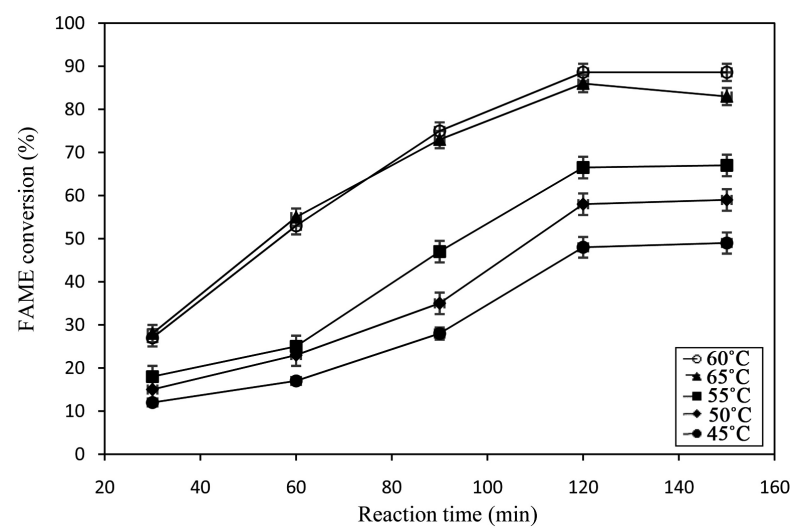

Figure 2. Variation of conversion to FAME with time at different temperatures $(2.5 \mathrm{wt} \%$, 33:1 methanol/oil molar ratio, $2 \mathrm{~h}$ ).

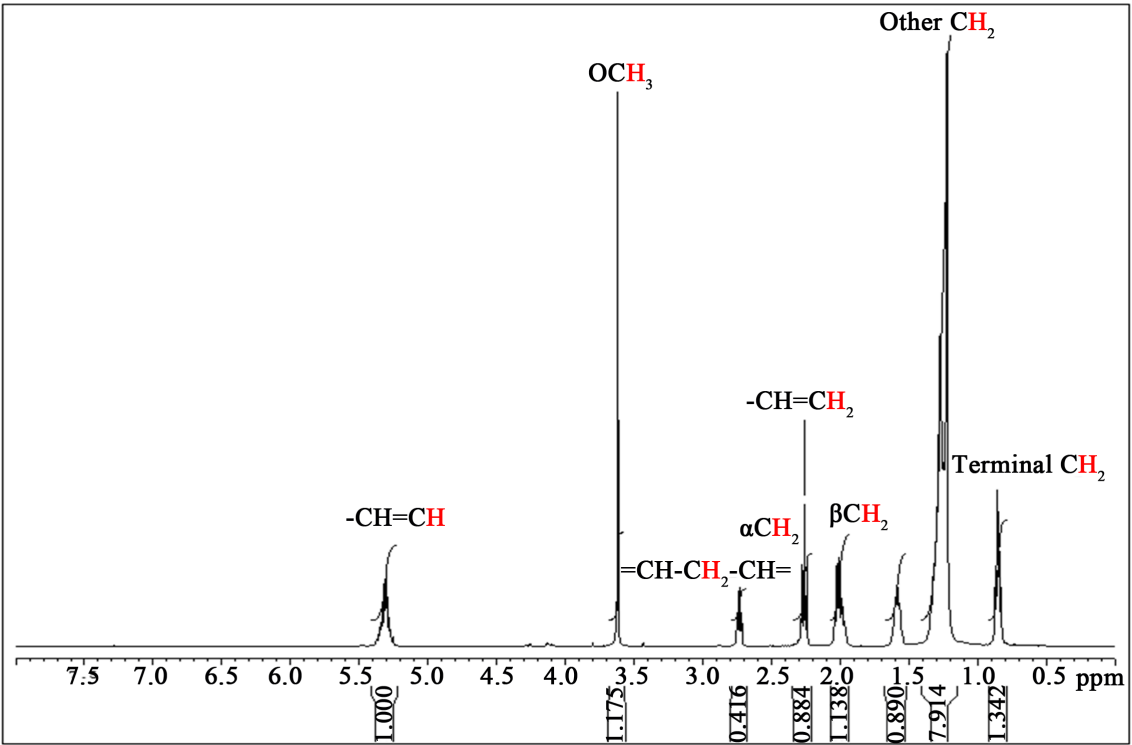

Figure 3. ${ }^{1} \mathrm{H}$ NMR spectra of FAME (biodiesel).

Table 4. ${ }^{1} \mathrm{H}$ NMR characteristic peaks of FAME and corresponding cottonseed oil.

\begin{tabular}{|c|c|c|c|}
\hline \multirow{2}{*}{ Proton (s) } & \multirow{2}{*}{ Functional group } & \multicolumn{2}{|c|}{ Chemical shift, $\delta(\mathrm{ppm})$} \\
\hline & & Oil & Biodiesel \\
\hline $\mathrm{CH}_{3}-\mathrm{C}$ & Terminal methyl group & $0.80-1.01$ & $0.8-1.0$ \\
\hline$-\left(\mathrm{CH}_{2) \mathrm{n}^{-}}\right.$ & Backbone $\mathrm{CH}_{2}$ & $1.20-1.41$ & $1.22-1.42$ \\
\hline$-\mathrm{CH}_{2} \mathrm{CH}_{2}-\mathrm{COOH}$ & $\beta$-methylene proton & $1.53-1.70$ & $1.55-1.69$ \\
\hline$=\mathrm{CH}_{-}-\mathrm{CH}_{2-}$ & $\alpha$-methylene group to one double bond & $1.94-2.11$ & $1.93-2.10$ \\
\hline $\mathrm{CH}_{2} \mathrm{COOR}$ & $\alpha$-methylene group to ester & 2.31 & 2.31 \\
\hline$=\mathrm{CH}-\mathrm{CH}_{2}-\mathrm{CH}=$ & $\alpha$-methylene group to two double bonds & 2.76 & 2.77 \\
\hline$-\mathrm{COOCH}_{3}$ & Methyl group of ester & - & 3.67 \\
\hline$-\mathrm{CH}_{2} \mathrm{OCOR}$ & Methylene group $\left(\mathrm{C}_{1}\right.$ and $\left.\mathrm{C}_{3}\right)$ of glyceride & $4.09-4.34$ & - \\
\hline -CHOCOR & Methinine proton at $\mathrm{C}_{2}$ of glyceride & 5.25 & - \\
\hline$-\mathrm{CH}=\mathrm{CH}-$ & Olefeinic protons & $5.28-5.43$ & $5.27-5.41$ \\
\hline
\end{tabular}




\subsection{Kinetics of Reaction}

The relationship between $-\ln (1-\mathrm{X})$ and time for transesterification of cottonseed oil in methanol over the aminated poly(GMA) grafted flax fibres at various temperatures $\left(45^{\circ} \mathrm{C}-60^{\circ} \mathrm{C}\right)$ and 1:33 oil-methanol ratio, $2.5 \mathrm{wt} \%$ catalyst dosage are shown in Figure 4. The linear fitting of the data showed the suitability of the pseudo first order model especially at $60^{\circ} \mathrm{C}$. The apparent rate constants from the plots following this pseudo first order model at different temperatures are given in Figure 5. The reaction rate increased with the increase in the temperature and reached a value of $0.00345\left(3.45 \times 10^{-3}\right) \mathrm{min}^{-1}$ at a temperature of $60^{\circ} \mathrm{C}$ beyond which it slightly declined to $0.00305\left(3.05 \times 10^{-3}\right) \mathrm{min}^{-1}$ with rise of temperature $65^{\circ} \mathrm{C}$. This is online with the effect of temperature on conversion cotton seed oil to FAME presented in Figure 2. Similar reaction rate constant increasing trend was reported for transesterification of soybean oil and methanol using calcium methoxide at different reaction temperatures $\left(55^{\circ} \mathrm{C}-65^{\circ} \mathrm{C}\right)$ [34]. It note worth mentioning that the low values of apparent reaction rate constants in the present study suggests that the mass transfer limitations are minimal in the present transesterification reaction and confirms that the kinetics of biodiesel production is controlled by the adsorption of methanol onto the active sites of the catalyst. Similar observation was reported in literature for transesterification of cotton seed oil with methanol over calcined clam shell catalyst [35].

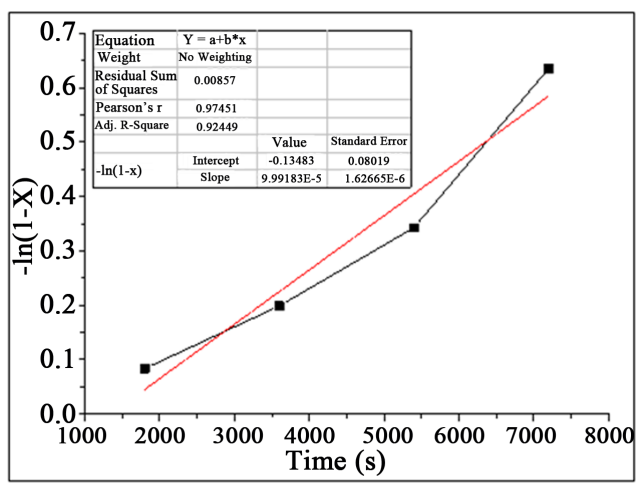

(a)

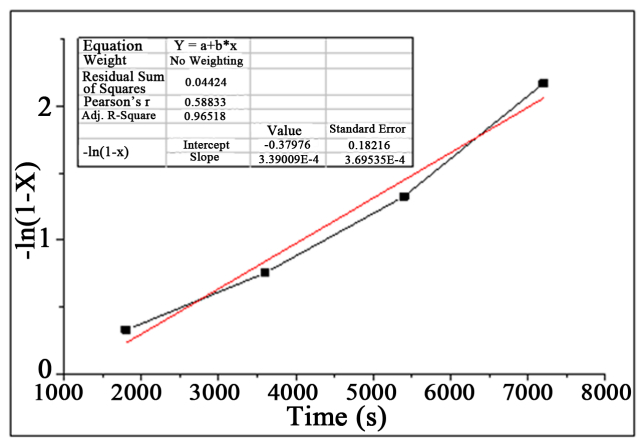

(c)

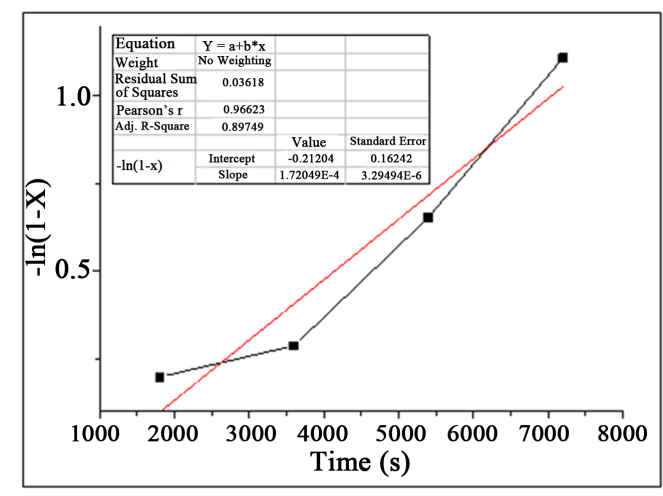

(b)

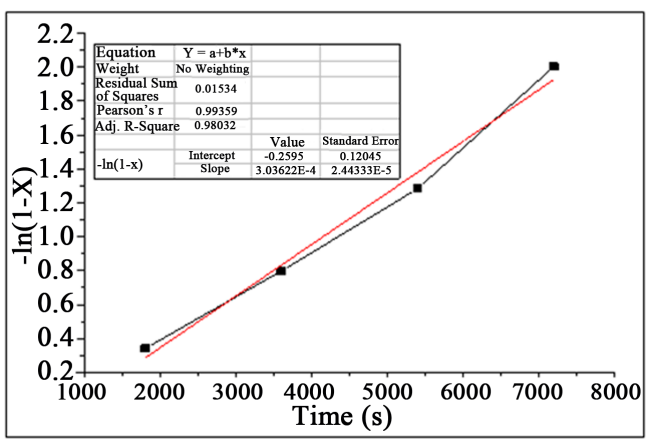

(d)

Figure 4. Plots of $-\ln (1-\mathrm{X})$ vs. time for transesterification of cottonseed oil in methanol over aminated poly(GMA) grafted flax fibres: (a) $45^{\circ} \mathrm{C}$; (b) $50^{\circ} \mathrm{C}$; (c) $55^{\circ} \mathrm{C}$ and (d) $60^{\circ} \mathrm{C}$ (reaction conditions: 1:33 oil-methanol ratio, $2.5 \mathrm{wt} \%$ catalyst dosage). 


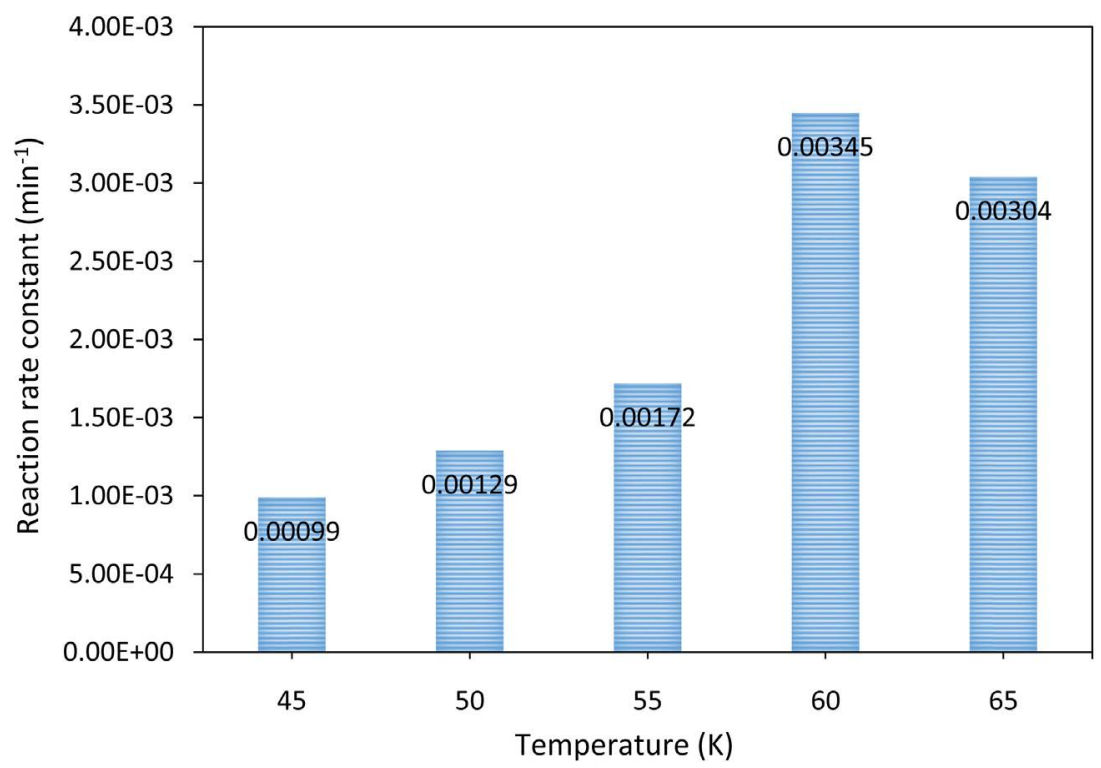

Figure 5. Variation of apparent reaction rate constant with temperature for transesterification of cottonseed oil with alkaline biopolymer catalyst.

The values of $E_{a}$ was obtained from the Arrhenius plot showing $\ln k$ versus $1 / \mathrm{T}$ as depicted in Figure 6 . The $\mathrm{E}_{\mathrm{a}}$ was found to be $69.33 \mathrm{~kJ} \cdot \mathrm{mol}^{-1}$. It is well established that the $\mathrm{E}_{\mathrm{a}}$ values can also be used to determine whether a reaction is controlled by kinetics or mass transfer. When $\mathrm{E}_{\mathrm{a}}$ values are within the range 26 $82 \mathrm{~kJ} \cdot \mathrm{mol}^{-1}$, the reaction is controlled by kinetics, otherwise it is controlled by mass transfer effect [20]. Therefore, it can be concluded that the transesterification of cottonseed oil with methanol using the aminated flax fibres in the present study is kinetically controlled and is free of mass transfer limitation.

\subsection{Thermodynamics}

Figure 7 shows the Eyring plot for transesterification of cottonseed oil in methanol over aminated poly(GMA) grafted flax fibres, which was used to obtain the $\Delta H^{*}$ of the reaction according to Equation (4). The $\Delta H^{*}$ was found to be $66.62 \mathrm{~kJ} \cdot \mathrm{mol}^{-1}$. The positive value of $\Delta H^{*}$ indicates that the reaction is endothermic and the aminated catalyst with highest active site has the lowest energy requirement for the reaction. This leads to the highest conversion rate, which is in a close agreement with kinetics study.

The $\Delta S^{*}$ was obtained from the intercept of Eyring equation plot expressed in Equation (5) and was found to be $-113.269 \mathrm{~kJ} \cdot \mathrm{mol}^{-1}$. The negative value of $\Delta S^{*}$ confirms that the transesterification reaction with the present catalyst is reversible in nature. It can be suggested that there is an associative reaction mechanism in which reactant species might have joined together over the present catalyst surface to form a more ordered transition state species and is going along with the kinetic study [20]. The negative value of $\Delta S^{*}$ also reveals there is a better degree of ordered geometry/alignment of the transition state compared to the ground state and this consistent with the literature [36]. 


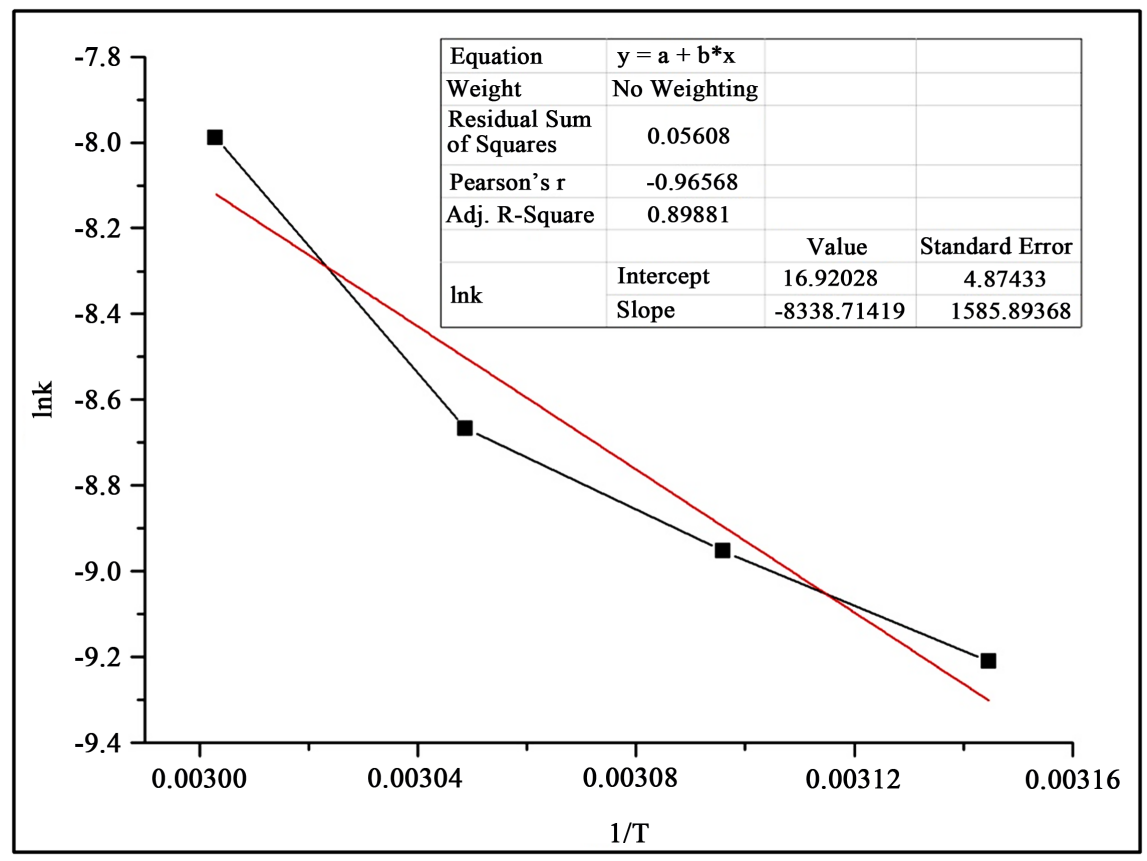

Figure 6. Arrhenius plot of $\ln \mathrm{k}$ vs. 1/T for transesterification of cottonseed oil in methanol over aminated poly(GMA) grafted flax fibres (reaction conditions are as in Figure 3).

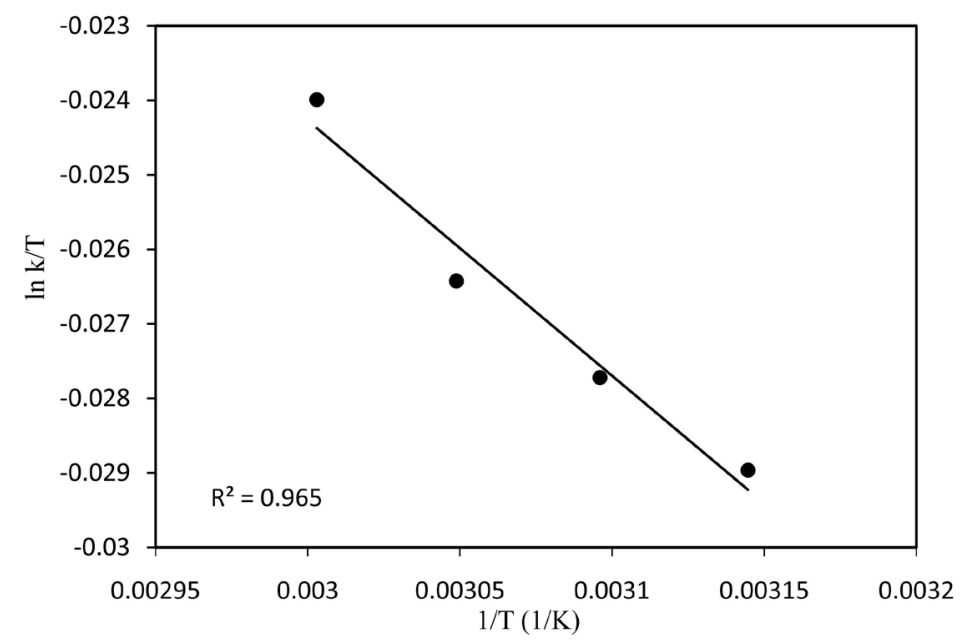

Figure 7. Eyring plot for transesterification of cottonseed oil in methanol over aminated poly(GMA) grafted flax fibres.

The $\Delta G^{*}$ at $60^{\circ} \mathrm{C}$ was calculated from Equation (6) and found to be 104 $\mathrm{J} \cdot \mathrm{mol}^{-1} \cdot \mathrm{K}^{-1}$. The positive values of $\Delta G^{*}$ confirms that the reaction is endothermic, reversible and non-spontaneous. Accordingly, the reactants need a heat input in order to transfer reactants to the transition state so as to give products [36]. Table 5 summarizes the values of the thermodynamic parameters.

\subsection{Physico-Chemical Properties of Biodiesel}

The key fuel quality parameters of FAME were determined and the obtained data is presented in Table 6. The density and kinematic viscosity of FAME was 
Table 5. Thermodynamic parameters for biodiesel conversion by alkaline catalyst.

\begin{tabular}{ccc}
\hline$\Delta H^{*}\left(\mathrm{~kJ} \cdot \mathrm{mol}^{-1}\right)$ & $\Delta S^{*}\left(\mathrm{~J} \cdot \mathrm{mol} \cdot \mathrm{K}^{-1}\right)$ & $\Delta G^{*}\left(\mathrm{~J} \cdot \mathrm{mol} \cdot \mathrm{K}^{-1}\right)$. \\
\hline 66.62 & -113.269 & 104 \\
\hline
\end{tabular}

Table 6. List of the specifications ASTM biodiesel standard test.

\begin{tabular}{cc}
\hline Quality test & Values \\
\hline Pour point $(\mathrm{min})$ & 0 \\
Kinematic viscosity at $40^{\circ} \mathrm{C}\left(\mathrm{mm}^{2} \cdot \mathrm{s}^{-1}\right)$ & 4.2 \\
Flash point $\left({ }^{\circ} \mathrm{C}\right)$ & 130 \\
Density at $30^{\circ} \mathrm{C}\left(\mathrm{mg} \cdot \mathrm{cm}^{-3}\right)$ & 0.8127 \\
Cloud point $\left({ }^{\circ} \mathrm{C}\right)$ & 7 \\
Cetane number & 54
\end{tabular}

found to be $0.8127 \mathrm{mg} \cdot \mathrm{cm}^{-3}$ and $2.4 \mathrm{~mm}^{2} \cdot \mathrm{s}^{-1}$, respectively. The latter was reduced from 33.1 in the cottonseed oil to 4.2 thereby improving the FAME atomisation properties. The pour point is found to be zero, which is going along with literature [37]. The flash point equals $130^{\circ} \mathrm{C}$, which is lower than that of cottonseed oil and far higher than that of petroleum diesel $\left(55^{\circ} \mathrm{C}-66^{\circ} \mathrm{C}\right)$ suggesting its suitability for use as a fuel [25]. It can be concluded that the biodiesel obtained from the transesterification cottonseed oil/methanol mixtures using the present aminated grafted flax fibres catalyst has good characteristics in terms of its physiochemical properties and this further confirms the potential of the biopolymer catalyst for such application.

\subsection{Catalyst Deactivation}

The deactivation of the obtained catalyst used in this study was examined in relation with the loss in both conversion to FAME and catalyst weight and the data is presented in Figure 8. As can be seen, the conversion to FAME remained stable in the first two cycles then decreased by about $17 \%$ and $49 \%$ in the third and fourth cycles, respectively. This was accompanied by a negligible loss in the catalyst weight in $2^{\text {nd }}$ cycle and such weight loss was increased in the $3^{\text {rd }}$ and $4^{\text {th }}$ cycles. This trend indicates that the catalytic activity was maintained in the first two cycles beyond, which it started to decline gradually with the increase in the number of cycles of transesterification reactions. Thus, the decrease in the catalytic activity is suggested to be mainly due to the detachment (degradation) of some of the amine groups represented by catalyst weight loss and this most likely took place during the process of regeneration with $\mathrm{NaOH}$ and citric acid. It can be suggested that the Flax-g-poly(GMA)/DEA catalyst has a reasonable stability taking into account its natural polymer substrate. 


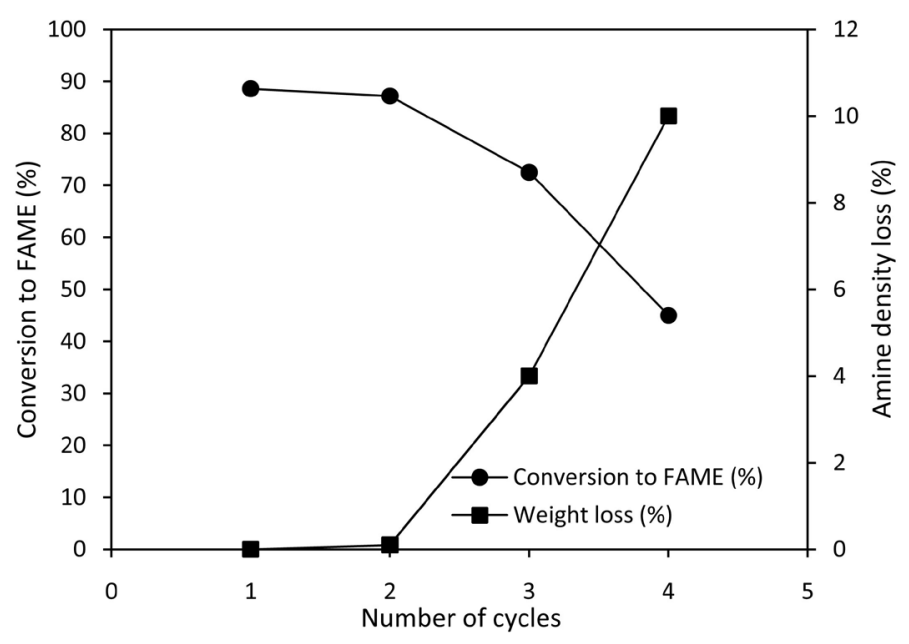

Figure 8. Variation of: ( ) conversion to FAME and ( weight loss in the catalyst with the number of cycles.

\section{Conclusion}

A new alkaline biopolymer catalyst based on delignified flax fibres grafted with poly(GMA) and loaded with alkalised DEA was successfully prepared and tested for transesterification of cottonseed oil in the presence of excess methanol to FAME. The kinetic and thermodynamic parameters of the reaction were established. The results showed a temperature-dependent transestification reaction and a maximum biodiesel conversion of $88.6 \%$ under the optimised conditions. Kinetic analysis revealed that the reaction followed the pseudo first order model and has a low activation energy of $69.33 \mathrm{~kJ} \cdot \mathrm{mol}^{-1}$ and an apparent rate constant of 0.00349 $\min ^{-1}$ at $60^{\circ} \mathrm{C}$. This clearly indicates that the catalytic process was kinetically controlled and independent of mass transfer limitation. The thermodynamic parameters such as $\Delta H^{*}, \Delta S^{*}$ and $\Delta G^{*}$ were found to be $66.62 \mathrm{~kJ} \cdot \mathrm{mol}^{-1}, 113.269$ and 104 $\mathrm{J} \cdot \mathrm{mol}^{-1} \cdot \mathrm{K}^{-1}$, respectively. This suggests that the transesterification process is reversible, non-spontaneous and endothermic. The activity of the catalyst was reasonably maintained for the first 2 cycles before it was undermined by the loss of some of the grafted aminated groups. It can be concluded that the biopolymer based alkaline catalyst produced high biodiesel conversion comparable to other heterogeneous catalysts despite its degradable nature and it offers greater advantages based on production costs, environmental friendliness and sustainable materials development.

\section{Acknowledgements}

The authors wish to thank Malaysian Ministry of Higher Education (MOHE) for the financial support from FRGS grant (Vot. No.: Q.J130000.2543.05H16). R. M. Moawia is grateful for the Malaysian International fellowship from MOHE.

\section{Conflicts of Interest}

The authors declare no conflicts of interest regarding the publication of this paper. 


\section{References}

[1] Gashaw, A., Getachew, T. and Teshita, T. (2015) A Review on Biodiesel Production as Alternative Fuel. Journal of Forest Products and Industries, 4, 80-85.

[2] Narasimharao, K., Lee, A.F. and Wilson, K. (2007) Catalysts in Production of Biodiesel: A Review. Journal of Biobased Material and Energy, 1, 19-30.

[3] Atadashi, I.M., Aroua, M.K., Abdul Aziz, A.R. and Sulaiman, N.M.N. (2013) The Effect of Catalysed in Biodiesel Production: A Review. Journal of Industrial and Engineering Chemistry, 19, 14-26. https://doi.org/10.1016/j.jiec.2012.07.009

[4] Endalew, A.K., Kiros, Y. and Zanzi, R. (2011) Inorganic Heterogeneous Catalysts for Biodiesel Production from Vegetable Oils. Biomass and Bioenergy, 35, 3787-3809. https://doi.org/10.1016/j.biombioe.2011.06.011

[5] Dehkhoda, A.M., West, A.H. and Naoko, E. (2010) Biochar Based Solid Acid Catalyst for Biodiesel Production. Applied Catalysis A: General, 382, 197-204. https://doi.org/10.1016/j.apcata.2010.04.051

[6] Van de Steene, E., De Clercq, J. and Thybaut, J.W. (2014) Ion-Exchange Resin Catalyzed Transesterification of Ethyl Acetate with Aethanol: Gel versus Ion-Exchange Resin. Chemical Engineering Journal, 242, 170-179. https://doi.org/10.1016/j.cej.2013.12.025

[7] Bing, Y., Hailin, C., Hua, Y., Xuesong, L., Mingming, J. and Wang, D. (2014) Nano/Microstructured Ion Exchange Resins and Their Applications. Journal of Nanoscience Nanotechnology, 14, 1790-1798. https://doi.org/10.1166/jnn.2014.8902

[8] Guilera, J., Bringué, R., Ramírez, E., Iborra, M. and Tejero, J. (2012) Synthesis of Ethyl Octyl Ether from Diethyl Carbonate and 1-Octanol over Solid Catalysts. A Screening Study. Applied Catalysis: A General, 413-414, 21-29. https://doi.org/10.1016/j.apcata.2011.10.037

[9] Ueki, Y., Mohamed, N.H., Seko, N. and Tamada, M. (2011) Rapid Biodiesel Fuel Production Using Novel Fibrous Catalyst Synthesized by Radiation-Induced Graft Polymerization. International Journal of Organic Chemistry, 1, 20-25. https://doi.org/10.4236/ijoc.2011.12004

[10] Ueki, Y., Saiki, S., Shibata, T., Hoshina, H., Kasai, N. and Seko, N. (2014) Optimization of Grafted Fibrous Polymer as a Solid Basic Catalyst for Biodiesel Fuel Production. International Journal of Organic Chemistry, 4, 91-105. https://doi.org/10.4236/ijoc.2014.42011

[11] Nasef, M.M., Alinezhad, S.S., Mat, R., Shabanzadeh, P., Yusof, R., Zakeri, M. and Farag, H. (2016) Preparation of Alkaline Polymer Catalyst by Radiation Induced Grafting for Transesterification of Triacetin under Neural Network Optimized Conditions. Journal of Macromolecular Science, 53, 557-565. https://doi.org/10.1080/10601325.2016.1201751

[12] Moawia, R.M., Nasef, M.M., Mohamed, N.H. and Ripin, A. (2016) Modification of Flax Fibres by Radiation Induced Emulsion Graft Copolymerization of Glycidyl Methacrylate. Radiation Physics and Chemistry, 122, 35-42. https://doi.org/10.1016/j.radphyschem.2016.01.008

[13] Zabaruddin, N.H., Mohamed, N.H., Abdullah, L.C., Tamada, M., Ueki, Y., Seko, N. and Choong, T.S.Y. (2019) Palm Oil-Based Biodiesel Synthesis by Radiation-Induced Kenaf Catalyst Packed in a Continuous Flow System. Industrial Crops and Products, 136, 102-109. https://doi.org/10.1016/j.indcrop.2019.04.069

[14] Moawia, R.M., Nasef, M.M. and Mohamed, N.H. (2016) Radiation Grafted Natural Fibres Functionalized with Alkalised Amine for Transesterification of Cottonseed 
Oil to Biodiesel. Jurnal Teknologi (Sciences \& Engineering), 78, 89-93. https://doi.org/10.11113/jt.v78.9571

[15] Kromer, K.-H. (2009) Physical Properties of Flax Fibre for Non-Textile-Use. Research and Agriculture Engineering, 55, 52-61. https://doi.org/10.17221/6/2008-RAE

[16] Economy, J., Dominguez, L. and Mangun, C.L. (2002) Polymeric Ion-Exchange Fibres. Industrial Engineering and Chemistry Research, 41, 6436-6442. https://doi.org/10.1021/ie0204641

[17] Kitakawa, N.S., Honda, H., Kuribayashi, S., Toda, T., Fukumura, T. and Yonemoto, T. (2007) Biodiesel Production Using Anionic Ion-Exchange Resin as Heterogeneous Catalyst. Bioresource Technology, 98, 416-421. https://doi.org/10.1016/j.biortech.2005.12.010

[18] Gelbard, G., Brès, O., Vargas, R.M., Vielfaure, F. and Schuchardt, U.F. (1995) ${ }^{1} \mathrm{H}$ Nuclear Magnetic Resonance Determination of the Yield of the Transesterification of Rapeseed Oil with Methanol. Journal of the American Oil Chemists' Society, 72, 1239-1241. https://doi.org/10.1007/BF02540998

[19] Song, R., Tong, D., Tang, J. and Hu, C. (2011) Effect of Composition on the Structure and Catalytic Properties of KF/Mg-La Solid Base Catalysts for Biodiesel Synthesis via Transesterification of Cottonseed Oil. Energy Fuels, 25, 2679-2686. https://doi.org/10.1021/ef200378j

[20] Kaur, N. and Ali, A. (2015) Biodiesel Production via Ethanolysis of Jatropha Oil Using Molybdenum Impregnated Calcium Oxide as Solid Catalyst. RSC Advances, 5, 13285-13295. https://doi.org/10.1039/C4RA14786C

[21] Ahmad, A.L., Yasin, N.H.M., Derek, C.J.C. and Lim, J.K. (2013) Kinetic Studies and Thermodynamics of Oil Extraction and Transesterification of Chlorella sp. for Biodiesel Production. Environmental Technology, 35, 891-897. https://doi.org/10.1080/09593330.2013.855263

[22] Balbino, J.M., Menezes, E.W.D., Benvenutti, E.V., Cataluna, R., Ebelinga, G. and Dupont, J. (2011) Silica-Supported Guanidine Catalyst for Continuous Flow Biodiesel Production. Green Chemistry, 13, 3111-3116.

https://doi.org/10.1039/c1gc15727b

[23] Onukwuli, D.O., Emembolu, L.N., Ude, C.N., Aliozo, S.O. and Menkiti, M.C. (2017) Optimization of Biodiesel Production from Refined Cotton Seed Oil and Its Characterization. Egyptian Journal of Petroleum, 26, 103-110. https://doi.org/10.1016/j.ejpe.2016.02.001

[24] Gopal, B.V., Sridevi, V., Sarma, A.J.N. and Rao, P.V. (2015) Processing and Characterization of Cotton Seed Methyl Ester. Austin Chemical Engineering, 2, 1020-1025.

[25] Venkatesan, H., John, G. and Sivamani, S. (2017) Cotton Seed Biodiesel as Alternative Fuel: Production and Its Characterization Analysis Using Spectroscopic Studies. Der Pharma Chemica, 9, 1-6.

[26] Chiplunkar, P.P. and Pratap, A.P. (2016) Utilization of Sun Flower Acid Oil for Synthesis of Alkyd Resin. Progressing Organic Coatings, 93, 61-67. https://doi.org/10.1016/j.porgcoat.2016.01.002

[27] Shimamoto, G.G., Favaro, M.M.A. and Tubino, M. (2015) Simple Methods via Mid-IR or ${ }^{1} \mathrm{H}$ NMR Spectroscopy for the Determination of the Iodine Value of Vegetable Oils. Journal Brazilian Chemical Society, 26, 1431-1437. https://doi.org/10.5935/0103-5053.20150111

[28] Vlahov, G. (1999) Application of NMR to the Study of Olive Oils. Progress in Nuclear Magnetic Resonance Spectroscopy, 35, 341-357. 
https://doi.org/10.1016/S0079-6565(99)00015-1

[29] Moawia, R.M., Nasef, M.M., Mohamed, N.H., Ripin, A. and Zakeri, M. (2019) Biopolymer Catalyst for Biodiesel Production by Functionalisation of Radiation Grafted Flax Fibres with Diethylamine under Optimised Conditions. Radiation Physics and Chemistry, 164, Article ID: 108375. https://doi.org/10.1016/j.radphyschem.2019.108375

[30] López, D.E., Goodwin, J.G., Bruce, D.A. and Lotero, E. (2005) Transesterification of Triacetin with Methanol on Solid Acid and Base Catalysts. Applied Catalysis A: General, 295, 97-105. https://doi.org/10.1016/j.apcata.2005.07.055

[31] Liu, Y., Wang, L. and Yan, Y. (2009) Biodiesel Synthesis Combining Pre-Esterification with Alkali Catalyzed Process from Rapeseed Oil Deodorizer Distillate. Fuel Processing Technology, 90, 857-862. https://doi.org/10.1016/j.fuproc.2009.04.005

[32] Sinha, D. and Murugavelh, S. (2016) Biodiesel Production from Waste Cotton Seed Oil Using Low Cost Catalyst: Engine Performance and Emission Characteristics. Perspectives in Science, 8, 237-240. https://doi.org/10.1016/j.pisc.2016.04.038

[33] Satyarthi, J.K., Srinivas, D. and Ratnasamy, P. (2009) Estimation of Free Fatty Acid Content in Oils, Fats and Biodiesel by ${ }^{1} \mathrm{H}$ NMR Spectroscopy. Energy Fuel, 23, 2273-2277. https://doi.org/10.1021/ef801011v

[34] Deshmane, V.G. and Adewuyi, Y.G. (2013) Synthesis and Kinetics of Biodiesel Formation via Calcium Methoxide Base Catalyzedtransesterification Reaction in the Absence and Presence of Ultrasound. Fuel, 107, 474-482.

https://doi.org/10.1016/j.fuel.2012.12.080

[35] Shobana, M., Prasad, R.K., Ragula, U.B.R. and Duraisamy Kumaresan, D. (2017) Kinetics and Characterization of Transesterification of Cottonseed Oil to Biodiesel Using Calcined Clam Shells as Catalyst. Biofuels, 5, 1-9. https://doi.org/10.1080/17597269.2017.1378994

[36] Nautiyal, P., Subramanian, K.A. and Dastidar, M.G. (2014) Kinetic and Thermodynamic Studies on Biodiesel Production from Spirulina platensis Algae Biomass Using Single Stage Extraction-Transesterification Process. Fuel, 135, 228-234. https://doi.org/10.1016/j.fuel.2014.06.063

[37] Karmakar, A., Karmakar, S. and Mukherjee, S. (2010) Properties of Various Plants and Animal's Feedstocks for Biodiesel Production. Bioresource Technology, 101, 7201-7210. https://doi.org/10.1016/j.biortech.2010.04.079 